\title{
A systemic review of randomized controlled studies about prevention with pharmacologic agents of adhesion formation in the rat uterine horn model
}

\author{
Gokalp Oner ${ }^{1}$, Pasa Ulug ${ }^{2}$
}

${ }^{1}$ Department of Obstetric and Gynecology, Mugla Sitki Kocman University, Mugla, Turkey
${ }^{2}$ Department of Obstetric and Gynecology, Erzincan University, Erzincan, Turkey

Submitted: 14 February 2014

Accepted: 9 May 2014

Arch Med Sci 2015; 11, 2: 274-281

DOI: $10.5114 /$ aoms.2014.47875

Copyright $\odot 2015$ Termedia \& Banach

\section{Abstract}

Introduction: Evaluation of treatment attempts in postoperative adhesion formation is pivotal for the prevention of several morbidities including infertility, pelvic pain, bowel obstruction, and subsequent intraoperative complications. The purpose of this systemic review was to assess the literature on the rat uterine horn model for adhesion formation and treatment modalities to prevent adhesion in the most frequently used experimental animal model. Material and methods: We performed a systemic review of publications from January $1^{\text {st }} 2000$ to December $31^{\text {st }} 2013$ via a PubMed search. A high number of agents were evaluated for the prevention of postoperative adhesion formation in the rat uterine horn model.

Results: According to most of the studies, adjuvants such as antiinflamatuars, antiestrogens, antioxidants were effective to prevent adhesion formation.

Conclusions: Prevention of adhesion formation is pivotal and numerous types of agents were described in the literature were summarized in this review.

Key words: adhesion, prevention, rat, uterine horn, systemic review.

\section{Introduction}

Adhesion formation is one of the major complications after pelvic surgery and occurs in 60-90\% of women after gynecological surgery [1]. Postoperative adhesion formation is associated with several morbidities including infertility, pelvic pain, bowel obstruction, and subsequent intraoperative complications [2, 3]. Adhesions account for approximately $20 \%$ of all infertility cases depending on a previous operation and adhesiolysis has been shown to increase pregnancy rates in more than $50 \%$ of infertile patients after previous laparotomy [4, 5]. However, the treatments of adhesions including adhesiolysis have an extra cost, hospitalization, and risks of surgery for the patients $[6,7]$. Therefore, prevention is much more significant than treatment in postoperative adhesions.

Although there are still major gaps in the pathophysiology of adhesion formation, the development of adhesion formation comprises the inflammatory response, exudation of fibrinogen and imbalance between fibrogenesis and fibrinolysis, blood coagulation, collagen synthesis, cell survival, proliferation, migration, adhesion and invasion, and angiogen-

\author{
Corresponding author: \\ Gokalp Oner \\ Department of Obstetric \\ and Gynecology \\ Erzincan University \\ Turkey 24100 Erzincan, \\ Turkey \\ Phone: 05062346822 \\ E-mail: onerg@yahoo.com
}




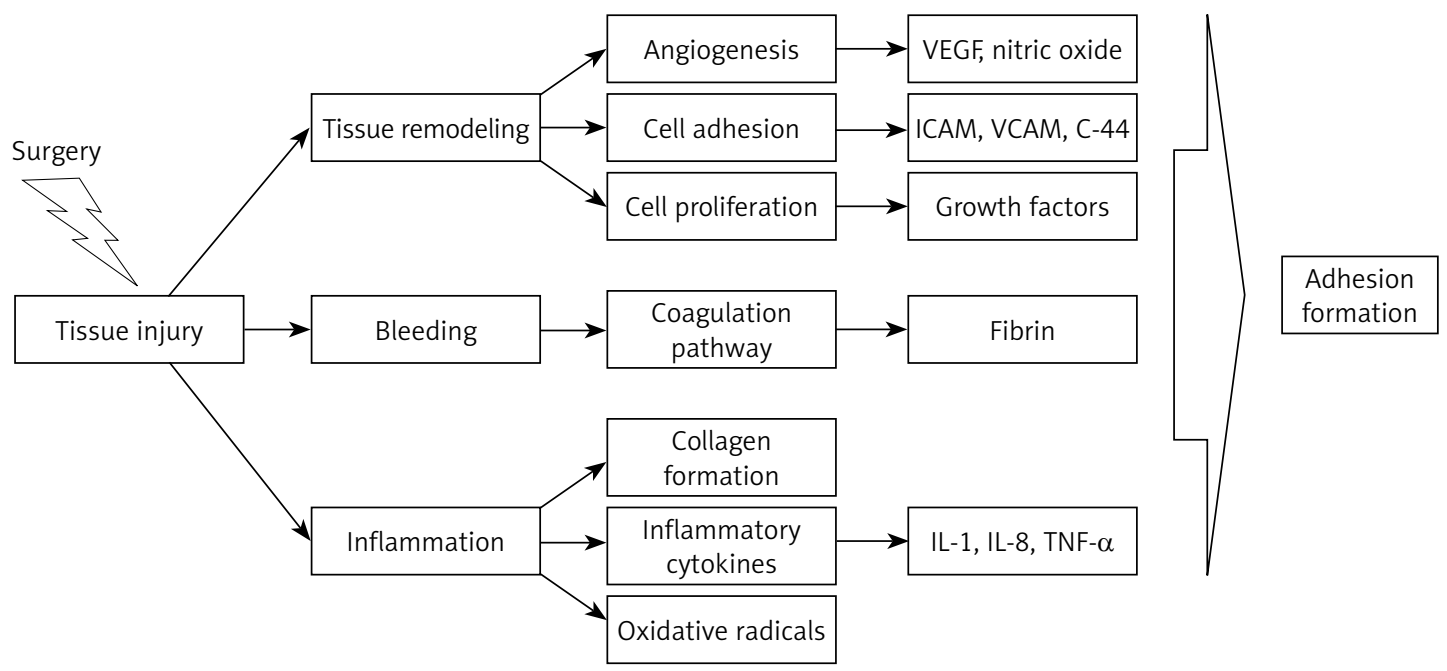

Figure 1. Mechanism of adhesion formation

esis [8]. The molecular pathways involved in these processes are all integrated (Figure 1). Additionally, treatment options in the rat model were performed to consider this pathophysiology. The purpose of these preventive agents was to activate fibrinolysis, hamper coagulation, diminish the inflammatory response, inhibit collagen synthesis or create a barrier between adjacent wound surfaces. In the literature there has been no systemic review focused on the prevention of adhesion formation in the most often used experimental rat model.

Development of peritoneal adhesions has been studied extensively in rat models, but to date there has been no definitive strategy to prevent their formation, as controversies concerning the effectiveness of available preventive agents still exist. In addition, there have been no recommendations or guidelines in the literature. This review summarizes the prevention strategies of postoperative adhesion formation in the rat uterine horn model that might in future enter clinical usage.

\section{Material and methods}

We performed a systemic review of the literature available in the PubMed database on experimental adhesion formation in the rat uterine horn model, published in English, from January $1^{\text {st }}$ 2000 to December $31^{\text {st }}$ 2013. Table I shows the list of medications used for this model. Available full text studies and randomized controlled trials were included in this review. Studies without the full text available, case reports, studies that used physical barriers to prevent adhesion formation, and other animal models for adhesion formation such as rabbits were excluded from this study. Inclusion criteria of this study were rat-based studies, studies using chemical agents, and adhesion formed in control groups. In adhesion formation of the rat uterine horn model, there have been sev- eral methods preferred to develop adhesions via monopolar or bipolar electrocautery and mechanical damage with a scalpel or both. In the studies, the adhesion model was mostly adapted from the system of Başbuğ et al. [9]. In this system, the uterine horns were visualized and a $2-\mathrm{cm}$ segment of each horn devascularized by creating a window, and traumatized in 10 spots on the anti-mesenteric surface using unipolar cautery. Sometimes absorbable sutures were applied on the serosal surface. All animals were killed within 14 days after surgery. Furthermore, adhesion formations between the groups were evaluated with macroscopic view and histological score or both.

\section{Results}

In Table I, the pharmacological agents used in the studies are presented with possible mechanisms of action. In Figure 1, the pathophysiological causes of adhesion formation after surgery are demonstrated by establishing the relation with Table I. Table II summarizes medications in studies, route of administration and doses of agents, technique of adhesion formation, and results and mechanisms of the trials. We found 34 studies on adhesion formation in the rat uterine horn model. Thirteen studies were excluded because of fulfilling exclusion criteria of this study. Twenty-one randomized controlled trials with 1047 rats were involved in this review. In the studies, adhesion formations have been scored with macroscopic and microscopic scoring systems. The macroscopic scoring system used by the adhesion model trials was mostly graded by the clinical adhesion scoring system of Linsky et al. [10]. In Linsky's system, the extent of adhesions was evaluated as follows: $0=$ no adhesion, $1=25 \%$ of surface covered, $2=50 \%$ of surface covered, 3 = completely covered. The severity of the adhesions was measured 
Table I. Effective pharmacological agents

1. Letrozole (anti-estrogenic effect of aromatase inhibitor)

2. Anastrozole (anti-estrogenic effect of aromatase inhibitor)

3. Leuprolide acetate (anti-estrogenic effect of $\mathrm{GnRH}$ agonist)

4. Cetrorelix (anti-estrogenic effect of $\mathrm{GnRH}$ antagonist)

5. Meloxicam (anti-inflammatory effect of COX2 inhibitor)

6. Resveratrol (anti-inflammatory effect of natural phenol)

7. Linezolid (anti-inflammatory effect of oxazolidinone)

8. Atorvastatin (anti-inflammatory effect of statin)

9. Metformin (anti-inflammatory effect of biguanide)

10. Sildenafil (anti-inflammatory effect of phosphodiesterase inhibitor)

11. Tadalafil (anti-inflammatory effect of phosphodiesterase inhibitor)

12. Trimetazidine (anti-oxidant effect of fatty acid oxidation inhibitor)

13. Ozone therapy (anti-oxidant effect)

14. Melatonin (anti-oxidant effect of $\mathrm{N}$-acetyl-5methoxytryptamine)

15. Type 1 collagen (anti-oxidant effect)

16. Rosiglitazone (anti-oxidant effect of PPAR- $\gamma$ agonist)

17. Medroxyprogesterone acetate (anti-estrogenic effect of progesterone)

18. Methylene blue (anti-oxidant effect)

19. Vitamin E (anti-oxidant effect)

20. Bevacizumab (fibrinolytic effect of angiogenesis inhibitor)

21. Ricinus oil (mechanic effect)

as follows: $0=$ no resistance to separation, 0.5 = some resistance, 1 = sharp dissection needed. The total score was obtained by the addition of two scores. Similarly, the extent and severity of the adhesions might be separately measured [11, 12]. These adhesion specimens were scored by the histological scoring system of Kanbour-Shakir et al. [13] according to the following characteristics: inflammation, fibroblastic activity, foreign body reaction, collagen formation, and vascular proliferation with the grading of 0 : none, 1: mild, 2: moderate, 3: marked, and 4: severe. Moreover, another histologic classification was used according to the adhesion classification based on the presence and extent of fibrosis [14].

\section{Discussion}

There have been several methods identified to reduce adhesion formation such as reduction of inflammatory response and oxidative radicals, inhibition of coagulation and fibrosis, promotion of fibrinolysis, immunomodulation, and mechanical separation with barriers. This review analyzed all of the rat uterine horn adhesion trials in which pharmacological agents were tested.

In two recent studies, the aromatase inhibitors letrozole and anastrozole significantly reduced macroscopic and histologic adhesion formation compared with tamoxifen and the control $[15,16]$. Results of tamoxifen were similar to the control in both studies and tamoxifen did not prevent adhesion. A hypoestrogenic milieu reduced estrogen-dependent angiogenic growth factors, epidermal growth factor and platelet-derived growth factor caused fibrovascular bands. Estrogen also may modulate the expression of vascular endothelial growth factor and basic fibroblast growth factor, which leads to expansion of capillary perfusion of the adhesion [16]. However, the exact mechanism of adhesion prevention effects for aromatase inhibitors is unclear. Considering the same pathophysiology, GnRH analogs and antagonist are used to prevent adhesion formation [17].

Inflammation develops in the first stage of the adhesion formation pathway after tissue injury, which is followed by an increase in vascular permeability and inflammatory cytokines. Therefore anti-inflammatory effects of agents including resveratrol, meloxicam, cyclooxygenase inhibitor nimesulide, and linezolid might have protective activity against adhesion formation in the rat uterine horn model [18-22]. Additionally, phosphodiesterase- 5 inhibitors diminished adhesion formation with local perfusion of nitric oxide and cGMP inhibition, which was pivotal in inflammation and collagen formation $[23,24]$. Studies showed that reactive oxygen radicals during ischemia led to an increase in vascular permeability and exudation, which play a role in the formation of adhesion [25]. Anti-oxidant effects of some drugs including trimetazidine were studied for the prevention of adhesion [26-28]. Atorvastatin and metformin reduced adhesion formation with the anti-inflammatory, antioxidant, and anti-fibrinolytic effects of drugs [29]. Ozçelik et al. were the first to show that melatonin, which has an antioxidant property, was effective in preventing adhesion formation [30]. Then combination treatment modalities with melatonin such as hyaluronate/carboxymethylcellulose membrane, type I collagen, and rosiglitazone were used to try to prevent adhesion formation and were found significantly effective [31-34]. Rosiglitazone with peroxisome proliferator-activated receptor- $\gamma$ agonist activity reduced the formation of intraperitoneal adhesion, possibly by reducing the initial inflammatory response and subsequent exudation [33]. In a study, the re- 


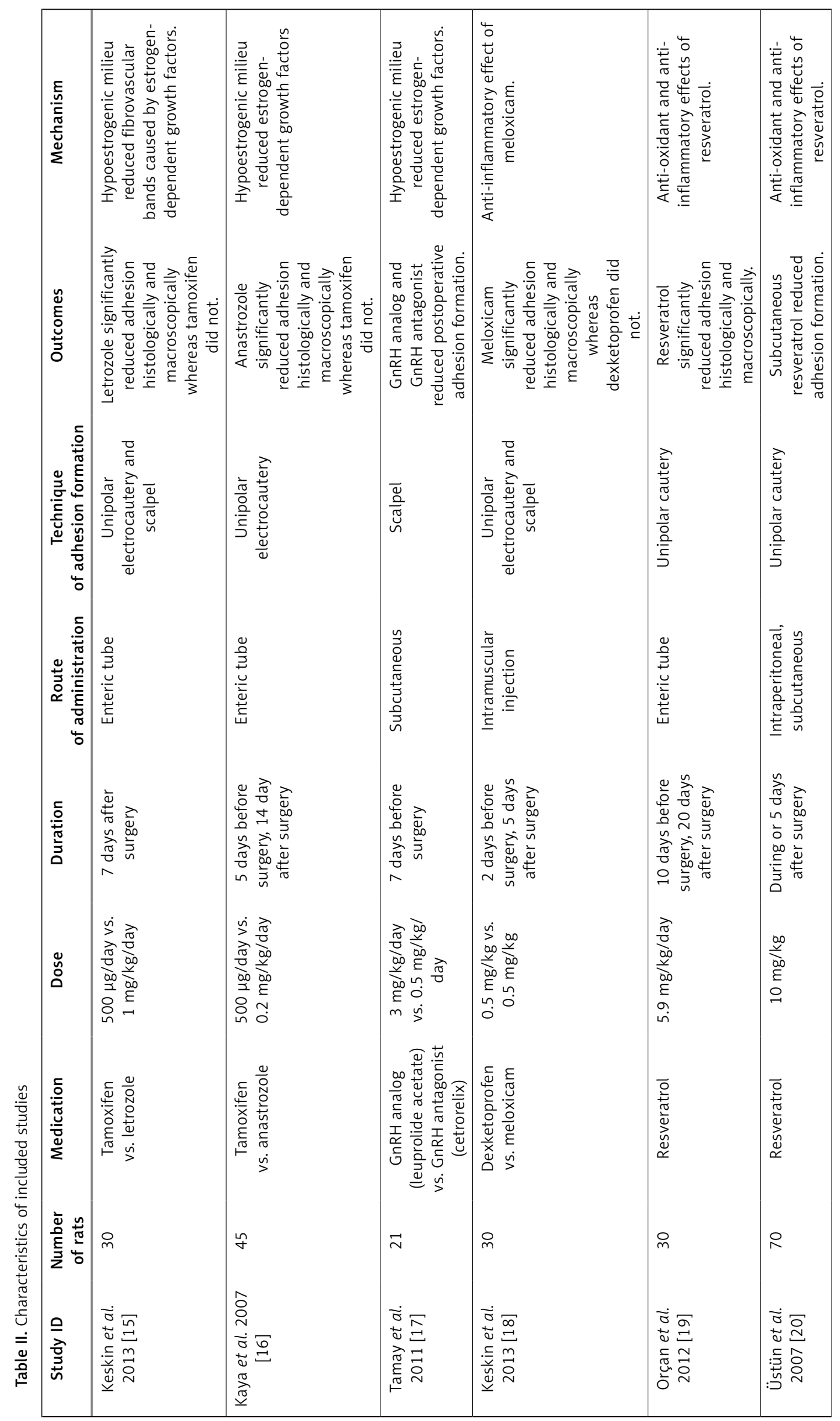




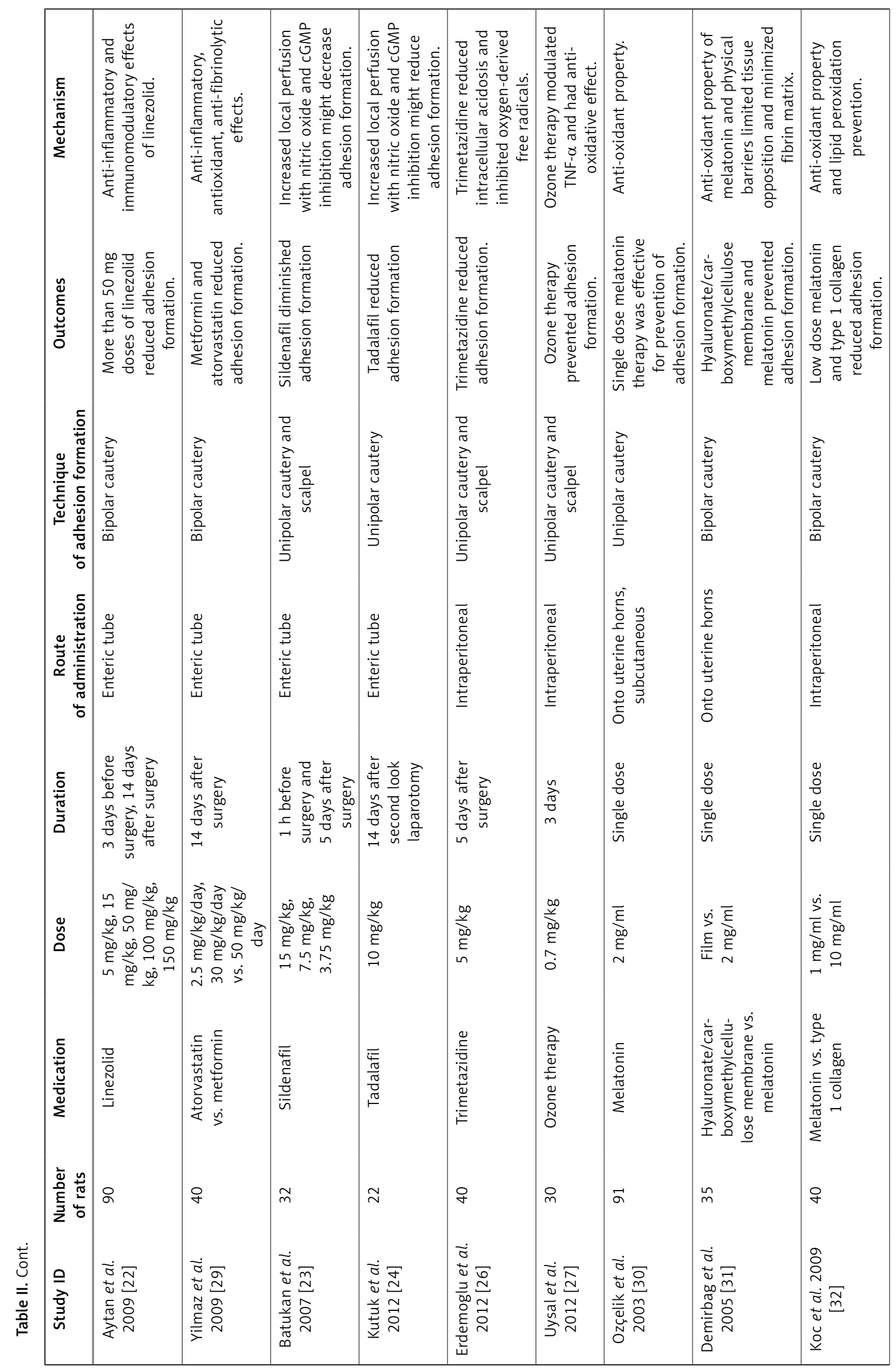




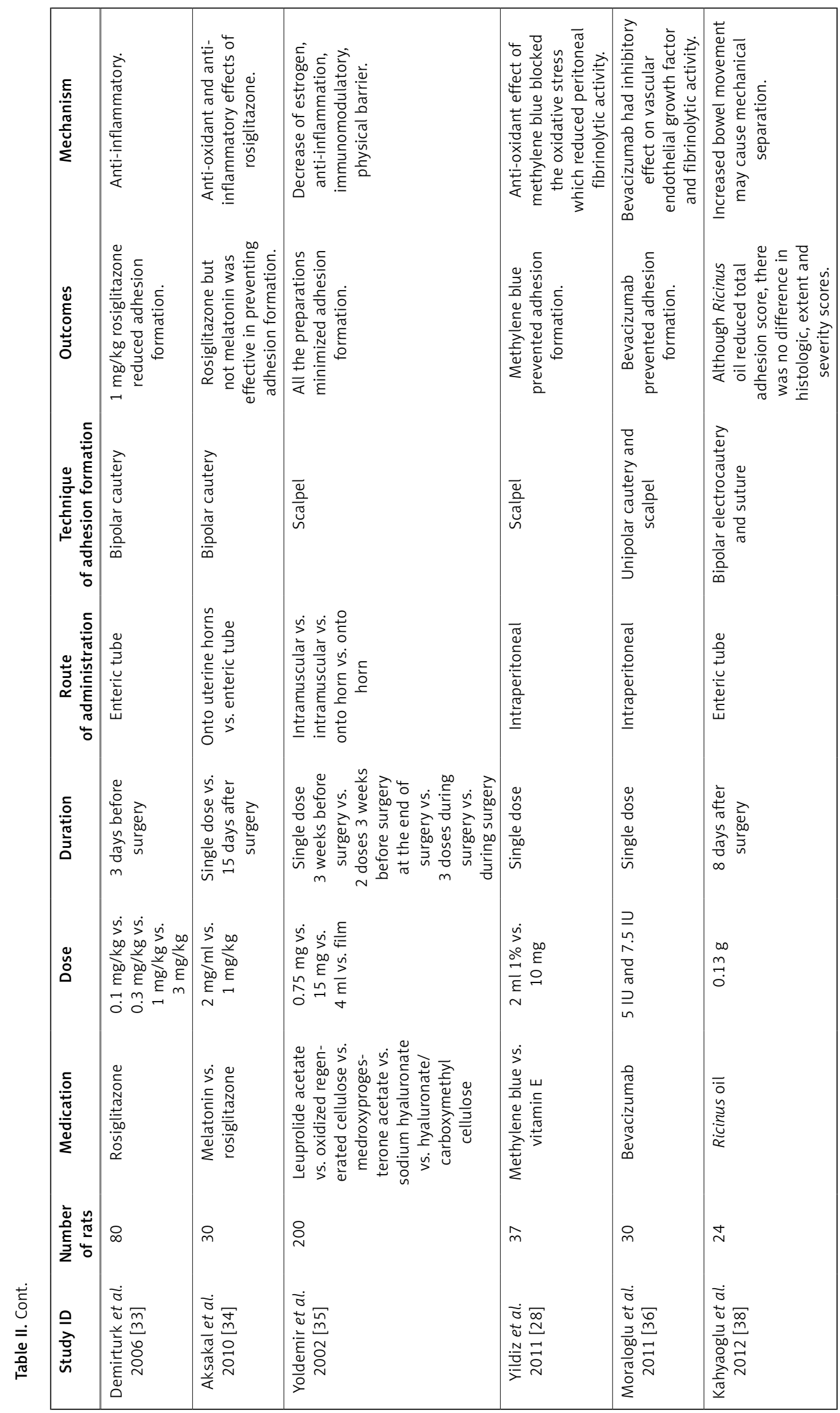


duction effect of two barriers, sodium hyaluronate and sodium hyaluronate/carboxymethylcellulose, and two pharmacological agents, medroxyprogesterone acetate and leuprolide acetate, was compared [35]. In this study, physical barrier effects, anti-inflammatory and immunomodulatory effects, and anti-estrogenic effects might be the reasons for the prevention of adhesion formation.

Fibrin and thrombin formation is a part of wound healing after injury, but the exaggeration in this formation is the main accused reason for adhesion formation. Thus, fibrinolytic and thrombolytic agents in the prevention of adhesion formation were examined in the rat uterine horn model [28, 36, 37].

Interestingly, oral Ricinus oil was used postoperatively for 8 days to prevent adhesion formation with the effect of increased bowel movements [38]. Therefore adhesion formation might be decreased by this mechanic effect. Although Ricinus oil reduced the total adhesion score, there was no difference in histologic, extent and severity scores of adhesion formation. The effects of lots of barriers were evaluated for preventing adhesion formation in the rat model and all of them had preventive action on adhesion formation with the effect of a physical barrier [39-42].

In this review, the agents were effective to prevent adhesion formation in rat models. However, these were preliminary studies and cannot be extrapolated to human beings. In fact, even immunological properties of the animals in the same species are not identical [43]. But small animal models such as the rat are the most frequently used models for screening experiments. Although it has advantages such as low cost, ease of handling, and ready availability, it has some controversial disadvantages such as inconsistency and unreliability. Animal models are the first step to analyze the effects of drugs on pathologies. When the efficacy and safety of agents are revealed in sufficient animal models, case reports and clinical investigations may begin. Adhesion formation is pivotal, especially in laparoscopic, infertility, and pelvic surgery [44]. Especially surgeries such as laparoscopic endometrioma, myoma uteri, and hydrosalpinx excisions are commonly used for the treatment of infertility [45]. However, the efficiency of these attempts is not clear. The main disadvantage and limitation of these operations is postoperative adhesion formation and anatomical disruption. Finally, prevention of adhesion formation after surgery must be taken into consideration.

In conclusion, analysis of the studies showed that most of the agents were effective for prevention of adhesion formation in the rat uterine horn model. This is the first review to analyze the trials about the prevention of adhesion formation with pharmacologic agents. Further studies evaluating the efficacy of the pharmacological agents in the experimental and clinical models are needed to clarify the prevention of adhesion formation after surgery.

\section{Conflict of interest}

The authors declare no conflict of interest.

\section{References}

1. Liakakos T, Thomakos N, Fine PM, Dervenis C, Young RL. Peritoneal adhesions: etiology, pathophysiology, and clinical significance. Recent advances in prevention and management. Dig Surg 2001; 18: 260-73.

2. Rodgers KE, Girgis W, St Amand K, Campeau J, diZerega GS. Reduction of adhesion formation in rabbits by intraperitoneal administration of lazaroid formulations. Hum Reprod 1998; 13: 2443-51.

3. Ellis H, Moran BJ, Thompson JN, et al. Adhesion-related hospital readmissions after abdominal and pelvic surgery: a retrospective cohort study. Lancet 1999; 353: 1476-80.

4. Holtz G. Prevention and management of peritoneal adhesions. Fertil Steril 1984; 41: 497-507.

5. di Zerega GS. Contemporary adhesion prevention. Fertil Steril 1994; 61: 219-35.

6. Ray NF, Larsen JW Jr, Stillman RJ, Jacobs RJ. Economic impact of hospitalizations for lower abdominal adhesiolysis in the United States in 1988. Surg Gynecol Obstet 1993; 176: 271-6.

7. Wallwiener D, Meyer A, Bastert G. Adhesion formation of the parietal and visceral peritoneum: an explanation for the controversy on the use of autologous and alloplastic barriers? Fertil Steril1998; 69: 132-7.

8. Wallwiener M, Brucker S, Hierlemann H, Brochhausen C, Solomayer E, Wallwiener C. Innovative barriers for peritoneal adhesion prevention: liquid or solid? A rat uterine horn model. Fertil Steril 2006; 86 (4 Suppl.): 1266-76.

9. Başbuğ M, Aygen E, Tayyar M, Kaya E, Narin F, Oktem O. Hyaluronic acid plus heparin for improved efficacy in prevention of adhesion formation in rat uterine horn model. Eur J Obstet Gynecol Reprod Biol 1998; 78: 109-12.

10. Linsky CB, Diamond MP, Cunningham T, Constantine B, De Cherney AH, di Zerega GS. Adhesion reduction in the rabbit uterine horn model using an absorbable barrier, TC-7. J Reprod Med 1987; 32: 17-20.

11. Knightly JJ, Agostino D, Cliffton EE. The effect of fibrinolysin and heparin on the formation of peritoneal adhesions. Surgery 1962; 52: 250-8.

12. Leach RE, Burns JW, Dawe EJ, Smith Barbour MD, Diamond MP. Reduction of postsurgical adhesion formation in the rabbit uterine horn model with use of hyaluronate/carboxymethyl cellulose gel. Fertil Steril 1998; 69: 415-8.

13. Kanbour-Shakir A, Kunz HW, Gill TJ 3rd, Armstrong DT, Macpherson TA. Morphologic changes in the rat uterus following natural mating and embryo transfer. Am J Reprod Immunol 1990; 23: 78-83.

14. Zühlke HV, Lorenz EM, Straub EM, Savvas V. Pathophysiology and classification of adhesions [German]. Langenbecks Arch Chir Suppl II Verh Dtsch Ges Chir 1990; 1009-16.

15. Keskin HL, Sirin YS, Keles H, Turgut O, Ide T, Avsar AF. The aromatase inhibitor letrozole reduces adhesion forma- 
tion after intraperitoneal surgery in a rat uterine horn model. Eur J Obstet Gynecol Reprod Biol 2013; 167: 199-204.

16. Kaya U, Oktem M, Zeyneloglu HB, Ozen O, Kuscu E. Impact of aromatase inhibitors on adhesion formation in a rat model. Fertil Steril 2007; 87: 934-9.

17. Tamay AG, Guvenal T, Micili SC, et al. Evaluation of the effects of gonadotropin-releasing hormone antagonist (GnRH-ant)and agonist ( $\mathrm{GnRH}-\mathrm{a})$ in the prevention of postoperative adhesion formation in a rat model with immunohistochemical analysis. Fertil Steril 2011; 96: 1230-3.

18. Keskin HL, Akkus SM, Sirin YS, et al. Comparison of the effects of meloxicam and dexketoprofen on postoperative adhesion formation in a rat uterine horn surgical model. J Minim Invasive Gynecol 2013; 20: 185-91.

19. Orçan S, Seven A, Isık H, et al. Resveratrolinhibits postoperative adhesion formation in a rat uterine horn adhesion model. Hum Fertil (Camb) 2012; 15: 217-20.

20. Üstün Y, Engin-Ustün Y, Ovayolu A, Meydanli MM, Temel I, Kafkasli A. The effect of resveratrol on prevention of the development of postoperative adhesions in a rat model. Gynecol Endocrinol 2007; 23: 518-22.

21. Guvenal T, Yanar O, Timuroglu Y, Cetin M, Cetin A. Effects of selective and non-selective cyclooxygenase (COX) in hibitors on postoperative adhesion formation in a rat uterine horn model. Clin Exp Obstet Gynecol 2010; 37 49-52.

22. Aytan H, Caliskan AC, Yener T, Demirturk F, Aytan P, Yenisehirli A. A novel antibiotic, linezolid, reduces intraperitoneal adhesion formation in the rat uterine horn model. Acta Obstet Gynecol Scand 2009; 88: 781-6.

23. Batukan C, Ozgun MT, Basbug M, Muderris II. Sildenafil reduces postoperative adhesion formation in a rat uterine horn model. Eur J Obstet Gynecol Reprod Biol 2007; 135: 183-7.

24. Kutuk MS, Ozgun MT, Batukan C, Ozcelik B, Basbug M, Ozturk A. Oral tadalafil reduces intra-abdominal adhesion reformation in rats. Hum Reprod 2012; 27: 733-7.

25. Tsimoyiannis EC, Lekkas ET, Paizis JB, Boulis SA, Page P, Kotoulas OB. Prevention of peritoneal adhesions in rats with trimetazidine. Acta Chir Scand 1990; 156: 771-4.

26. Erdemoglu E, Seçkin B, Günyeli I, Güney M, Seçkin M, Mungan T. Reduction of postoperative adhesions by trimetazidine: an experimental study in a rat model. Arch Gynecol Obstet 2012; 285: 757-61.

27. Uysal B, Demirbag S, Poyrazoglu Y, et al. Medical ozone therapy decreases postoperative uterine adhesion formation in rats. Arch Gynecol Obstet 2012; 286: 1201-7.

28. Yildiz H, Durmus AS, Simsek H, Yaman I. The comparison of methylene blue and vitamin $E$ in prevention of abdominal postoperative adhesion formation in rat uterine horn models: biochemical and histopathologic evaluation. Acta Cir Bras 2011; 26: 51-7.

29. Yilmaz B, Aksakal O, Gungor T, et al. Metformin and atorvastatin reduce adhesion formation in a rat uterine horn model. Reprod Biomed Online 2009; 18: 436-42.

30. Ozçelik B, Serin IS, Basbug M, Uludag S, Narin F, Tayyar M. Effect of melatonin in the prevention of post-operative adhesion formation in a rat uterine horn adhesion model. Hum Reprod 2003; 18: 1703-6.

31. Demirbag S, Cetinkursun S, Tasdemir U, Ozturk H, Pekcan M, Yesildaglar N. Comparison of hyaluronate/ carboxymethylcellulose membrane and melatonin for prevention of adhesion formation in a rat model. Hum Reprod 2005; 20: 2021-4.

32. Koc O, Duran B, Topcuoglu A, Bugdayci G, Yilmaz F, Dönmez $M$. Intraperitoneal administration of single dose type I collagen or low dose melatonin to prevent intraperitoneal adhesion formation: a comparative study. Eur J Obstet Gynecol Reprod Biol 2009; 145: 209-13.

33. Demirturk F, Aytan H, Caliskan A, et al. The effect of rosiglitazone in the prevention of intra-abdominal adhesion formation in a rat uterine horn model. Hum Reprod 2006; 21: 3008-13.

34. Aksakal O, Yilmaz B, Gungor T, et al. A randomised controlled trial on melatonin and rosiglitazone for prevention of adhesion formation in a rat uterine horn model. Arch Gynecol Obstet 2010; 282: 55-61.

35. Yoldemir T, Sagol S, Adakan S, Oztekin K, Ozsener S, Karadadas N. Comparison of the reduction of postoperative adhesions by two barriers, one solution, and two pharmacologic agents in the rat uterine model. Fertil Steril 2002; 78: 335-9.

36. Moraloglu O, Işik H, Kiliç S, et al. Effect of bevacizumab on postoperative adhesion formation in a rat uterine horn adhesion model and the correlation with vascular endothelial growth factor and Ki-67 immunopositivity. Fertil Steril 2011; 95: 2638-41.

37. Hellebrekers BW, Trimbos-Kemper TC, Trimbos JB, Emeis JJ, Kooistra T. Use of fibrinolytic agents in the prevention of postoperative adhesion formation. Fertil Steril 2000; 74: 203-12.

38. Kahyaoglu S, Timur H, Kaba M, Kahyaoglu I, Sirvan L, Cicek MN. Prevention of adhesion formation in Wistar-albino rats by increased bowel movements achieved with oral Ricinus oil use for 8 days postoperatively: an experimental study. Eur J Obstet Gynecol Reprod Biol 2012; 165: 337-41.

39. Arnold PB, Green CW, Foresman PA, Rodeheaver GT. Evaluation of resorbable barriers for preventing surgical adhesions. Fertil Steril 2000; 73: 157-61.

40. Kelekci S, Yilmaz B, Oguz S, Zergeroğlu S, Inan I, Tokucoğlu S. The efficacy of a hyaluronate/carboxymethylcellulose membrane in prevention of postoperative adhesion in a rat uterine horn model. Tohoku J Exp Med 2004; 204: 189-94.

41. Wallwiener M, Brucker S, Hierlemann H, Brochhausen C, Solomayer E, Wallwiener C. Innovative barriers for peritoneal adhesion prevention: liquid or solid? A rat uterine horn model. Fertil Steril 2006; 86 (4 Suppl.): 1266-76.

42. Washburn S, Jennell JL, Hodges SJ. Halofuginone- and chitosan-coated amnion membranes demonstrate improved abdominal adhesion prevention. Sci World J 2010; 10: $2362-6$

43. Wiseman DM. Correlations between animal and human models of adhesions. Infert Reprod Med Clin N Am 2003; 14: 391-401.

44. Jamry A, Jałyński M, Piskorz L, Brocki M. Assessment of adhesion formation after laparoscopic intraperitoneal implantation of Dynamesh IPOM mesh. Arch Med Sci 2013; 9: 487-92.

45. Duffy JM, Arambage K, Correa FJ, et al. Laparoscopic surgery for endometriosis. Cochrane Database Syst Rev 2014; 4: CD011031. 